\title{
Total flavonoids from Ampelopsis megalophylla suppress proliferation of vascular smooth muscle cells in vivo and in vitro
}

 \\ ${ }^{I}$ College of Pharmacy, Hubei University of Chinese Medicine, Wuhan, People's Republic of China, ${ }^{2}$ Laboratory of Chinese \\ Medicine Resource and Compound Prescription (Ministry of Education), Hubei University of Chinese Medicine, Wuhan, \\ People's Republic of China
}

\begin{abstract}
Various benefits of flavonoids for ameliorating cardiovascular diseases have been demonstrated. However, the lowering effects on blood pressure caused by antiproliferative potentials of flavonoids in vascular smooth muscle cells are rare. In this study, the antihypertensive effects of total flavonoids from Ampelopsis megalophylla were investigated. The dynamic pressure values and the rate of media thickness versus lumen diameter were measured by the tail-cuff system and H\&E staining in vivo, respectively. The mRNA expressions of ACE, Ang II, eNOS, c-Myc, cyclin D1 and p2 $7^{\text {Kipl } 1}$ in thoracic aorta or A7r5 cells were measured by qPCR, respectively. The protein expressions of c-Myc, Cyclin D1, p2 $7^{\mathrm{Kipl}}$ and $\beta$-catenin in tissues or A7r5 cells were measured by Western blot assay. Total flavonoids of $A$. megalophylla (TFAM) reduced the expressions of ACE and Ang II, and elevated the content of eNOS in thoracic aorta cells of SHRs. Furthermore, TFAM decreased the mRNA and protein expressions of c-Myc and cyclin D1 by repressing the $\mathrm{Wnt} / \beta$-catenin-mediated TCF/LEF transcriptional activation both in vivo and in vitro, which is synergetic with the up-regulation of $\mathrm{p} 27^{\mathrm{Kip} 1}$ expression. Our study provided evidence for developing flavonoids from A. megalophylla as herbal supplements to prevent against cardiovascular diseases by suppressing vascular remodeling.
\end{abstract}

Keywords: Ampelopsis megalophylla. Flavonoids/effects. Cardiovascular remodeling. $\beta$-Catenin.

\section{INTRODUCTION}

Although noticeable pharmacological achievement advances on the therapeutic strategy of hypertension, the epidemiological characteristics of hypertension are less optimistic. Hypertension remains an obsessional public health challenge globally. The amount of adults with hypertension in 2025 is forecasted to elevate by approximately $60 \%$ to aggregate 1.6 billion (Kearney et al., 2005). Hence, hypertension is unambiguously considered as the main cause of cardiovascular disease (CVD) (Graham et al., 2007). The pathological changes of hypertension are involved with the decline of cardiac-cerebral vascular function, including the proliferation of vascular smooth muscle cells, which contributes to vascular remodeling (Gibbons, Dzau, 1994). Generally, the long-term elevated blood pressure (BP) level at or above $140 / 90 \mathrm{mmHg}$ is

\footnotetext{
*Correspondence: G. Zheng. Hubei University of Chinese Medicine, Wuhan 430065 - People’s Republic of China. E-mail address: zgh1227@sina.com. \# These authors contributed equally to this work.
}

defined as essential hypertension (Gu et al., 2002).Some pharmacological agents have been applied to ameliorate hypertension. Because many of these agents require lifelong treatment, numerous patients still have poorly stabilized BP and suffer hypertensive complications.

Multiple plant-derived chemicals can significantly alleviate high BP (Herrera-Arellano et al., 2007; Xiong et $a l ., 2013)$. It has been indicated that dietary polyphenols may be beneficial to the prevention and treatment of hypertension (Galleano, Pechanova, Fraga, 2010). Flavonoids represent the major class of polyphenols, in addition to their antioxidant effects, which exhibit a comprehensive spectrum of pharmacological activities. Although the crucial roles of renin-angiotensin system (RAS), oxidative stress, and vascular remodeling have been elaborated in the development and the persistence of hypertension, the pathomechanism of hypertension is apparently complicated (Beevers, Lip, O'Brien, 2001). The emerging and largely consistent evidences demonstrate that flavonoids can improve endothelial function and may reduce blood pressure (Hodgson, 2006). For instance, 
the anthocyanin cyanidin-3-glucoside could increase the expression of endothelial Nitric Oxide Synthase (eNOS) in vascular endothelial cells. In fact, consumption of flavanolrich dark chocolate decreases BP and elevates insulin sensitivity in healthy volunteers. Further findings support a potentially beneficial action of flavanols in chocolate on BP and vasorelaxation in essential hypertensives (Grassi et al., 2005). Moreover, the flavonoid quercetin also reduces the elevated blood pressure, the cardiac and renal hypertrophy, and the dysfunctional vascular changes in spontaneously hypertensive rats (SHRs) (Duarte et al., 2001). Quercetin and its metabolites exhibit selective vasodilator effects toward the resistance vessels in the isolated rat thoracic and abdominal aorta (Perez-Vizcaino et al., 2002). Thus, using the natural flavonoids to moderate hypertension could be an effective complementary strategy to reduce the cardiocerebral vascular accidents.

Dihydromyricetin (DHM) is a kind of bioactive flavonoids and identified as the benefit constituent in the tender stems and leaves of Ampelopsis grossendentata (Zhang et al., 2007a). Pharmacokinetic studies of dihydromyricetin and myricetin in rat plasma by High Performance Liquid Chromatography with Diode Array Detector (HPLC-DAD) also have been assessed after oral administration of Ampelopsis grossedentata (Zhang et al., 2007b). In fact, dihydromyricetin is the main flavonoid in other ampelopsis, including in Ampelopsis megalophylla (See supporting information). The present study demonstrates that the ameliorative potential of total flavonoids in Ampelopsis megalophylla Diels et Gilg, a kind of flavonoid-rich tea resources which is consumed in Western Hubei (China), have effects on the Angiotensin II (Ang II), which is associated with the proliferation of vascular smooth muscle cells in both spontaneously hypertensive rats and $\mathrm{A} 7 \mathrm{r} 5$ vascular smooth muscle cells.

\section{MATERIAL AND METHODS}

\section{Plant collection and identification}

Medicinal materials were collected at the Enshi, Hubei in China during July 2012. A botanist at the Herbarium of Hubei University of Traditional Chinese Medicine identified and authenticated the plants as Ampelopsis megalophylla Diels et Gilg, and a voucher specimen 201207AM was preserved at the herbarium.

\section{Preparation of total flavonoids}

The leaves of $A$. megalophylla were naturally airdried and pulverized. The powders $(2.0 \mathrm{~kg})$ were extracted with ethanol $(95 \%, \mathrm{v} / \mathrm{v})$ under reflux for $4 \mathrm{~h}$ by three times. The filtrations were vacuum-concentrated to obtain a crude ethanol extract ( $540 \mathrm{~g})$. Then the crude extract was dissolved in water and filtrated. The water solution was subjected to polyamide gel column chromatography eluted with ethanol $(70 \%, v / v)$. Finally, the ethanol elution was merged and concentrated. The yield of total flavonoids was $3.4 \%$. Phytochemical analysis of the plant extracts has previously been carried out using standard procedures as reported (Xie et al., 2014). Dihydromyricetin and myricetin were analyzed quantitatively by HPLC-DAD, and considered as the major components in the extracts (total flavonoids of A. megalophylla, TFAM) (See Supporting information). The extract was dispersed in sodium chloride for further intragastric administration.

\section{Animals and in vivo experiment design}

The SHR model is a kind of classical hypertensive models, which is similar to primary hypertension in humans (Bauersachs et al., 1998). SHR is applied to identify antihypertensive agents because this model provides analogous pattern of molecular pathology as in hypertensive patients. From the early stage to the terminal stage, blood pressure is elevated gradually, which is attributed to progressively increased vascular resistance and continuously activated RAS. Therefore, SHRs (purchased from Vital River Laboratory Animal Technology Co., Ltd., Beijing, China) were used in present study. The SHRs received standard food and water ad libitum and at 22-24 ${ }^{\circ} \mathrm{C}$ in an artificial $12 \mathrm{~h} / 12 \mathrm{~h}$ light/dark cycle. The SHRs (20 weeks) were treated with TFAM-L, TFAM-M and TFAM-H twice a day at 10:00 and 15:00 from 4 to 10 week of the evaluation $(90,180,360 \mathrm{mg} / \mathrm{kg}$, respectively, diluted in drinking water, gavage administration).

\section{Blood pressure measurement}

Systolic blood pressure (SBP) was recorded noninvasively using tail-cuff system (Duarte et al., 2001) every 2 days. In brief, after pre-warming the SHRs at $36^{\circ} \mathrm{C}$ for $15 \mathrm{~min}, \mathrm{SBP}$ was measured every other week from the initiation of the evaluation. Mean blood pressures $(n=5)$ were obtained for each animal when the pressure value is relatively stable.

\section{Evaluation of vascular media thickness and lumen diameter of thoracic aorta}

To identify the effects of TFAM on vascular relaxation through endothelial-dependent mechanisms, 
the thoracic aorta segments of SHRs were separated immediately after euthanasia and stored in Phosphate Buffer Solution (PBS) at room temperature. After gross inspection of the segments, the intact regions were selected for further analysis. The thoracic aorta were intersected into sequential ring segments and further stained by using hematoxylin and eosin (H\&E) for determination of the media thickness and lumen diameter.

\section{Analysis of serum nitric oxide content}

After anesthetizing animals in the end of the experiment, the whole blood was obtained from the carotid artery of sacrificial animals and the serum was separated by centrifugation $(3000 \mathrm{rpm} / \mathrm{min})$. Nitrate reductase method was applied to determine the levels of nitric oxide using Nitric Oxide (NO) Assay Kit (Jiancheng, China) according to the manufacturer's manual.

\section{Reverse transcription and real-time quantitative PCR}

Total cellular RNA was isolated by using Trizol reagent (Invitrogen, USA), and first-strand cDNA synthesis with $1 \mu \mathrm{g}$ of RNA was performed using MMLV reverse transcriptase (Promega, USA), according to the manufacturer's instructions. The PCR profile was 95 ${ }^{\circ} \mathrm{C}$ for $2 \mathrm{~min}, 40$ cycles of $95{ }^{\circ} \mathrm{C}$ for $5 \mathrm{~s}, 55^{\circ} \mathrm{C}$ for $12 \mathrm{~s}$, and $55^{\circ} \mathrm{C}$ for $12 \mathrm{~s}$, followed by extension for $7 \mathrm{~min}$ at $72^{\circ} \mathrm{C}$. Verified primer sequences for amplifying mRNA of angiotensin converting enzyme (ACE), Ang II, c-Myc, p2 $7^{\mathrm{Kip} 1}$ and Bcl-2 were listed in Table I. The mRNA amount in different groups was normalized to relative expression of $\beta$-actin.

\section{Western blot}

Whole cell extracts and nucleoproteins were prepared as described (Wang et al., 2015). Equal amounts of samples were fractionated by sodium dodecyl sulfate polyacrylamide gel electropheresis (SDS-PAGE) of 15\% tricine gels and blotted onto polyvinylidene fluoride (PVDF) membranes by Trans-Blot Turbo Blotting System (Bio-Rad, USA). The following primary antibodies were used: c-Myc (9402S, Cell Signaling Technology (CST), Beverly, MA, USA), Cyclin D1 (2922S, CST, Beverly, MA, USA), p27 $7^{\text {Kip } 1}$ (2552S, CST, Beverly, MA, USA) and HRP-conjugated $\beta$-actin (5125S, CST, Beverly, MA, USA). For investigating the expression of $\beta$-catenin in nucleus, the protein-loaded membranes were probed with HRP-conjugated anti- $\beta$-catenin primary antibodies. The bands of target protein were analyzed using Image Lab 5.1 (Bio-Rad, USA). $\beta$-actin and Histone H3 (Sigma, USA) served as the internal control for quantitating protein expression in whole cell extracts (c-Myc, Cyclin D1 and $\left.\mathrm{p} 27^{\mathrm{Kip} 1}\right)$ and the nucleus extracts ( $\beta$-catenin), respectively.

\section{Cell culture, Ang II stimulus and CCK-8 assay}

A7r5 cells, which are the commercial cells derived from the aorta of fetal rat, were purchased from American Type Culture Collection (Rockville, MD, USA) and

TABLE I - Sequences of polymerase chain reaction (PCR) primer used in real-time PCR

\begin{tabular}{lcc}
\hline & Sequences (5' to 3') & Length (bp) \\
\hline$\beta$-actin & Forward CGTTGACATCCGTAAAGACCTC & 110 \\
& Reverse TAGGAGCCAGGGCAGTAATCT & \\
c-Myc & Forward CCAGCCAAGGTTGTGAGGTTAGG & 176 \\
& Reverse CAGACGTAAACAGCTCCGAA & \\
cyclin D1 & Forward GAACAAACAGATCATCCGCAAACAC & 231 \\
& Reverse TGCTCCTGGCAGGCCCGGAGGCAGT & \\
eNOS & Forward CTCAATGTCGTGTAATCGGTCT & 98 \\
& Reverse TCCACCGTTACCAGACAACTATCC & \\
ACE & Forward TCCACCGTTACCAGACAACTATCC & 119 \\
& Reverse CTGCGTATTCGTTCCACAACACCT & \\
Ang II & Forward AGCACGACTTCCTGACTTGGATAAA & 245 \\
p27 & Reverse AGACTCTGTGGGCTGCTCCTCCTC & \\
& Forward CATTCAATGGAGTCAGCGAT & 120 \\
\hline
\end{tabular}


incubated as previously described (Filipeanu et al., 2001). For investigating the effects of TFAM on the Ang IImediated vascular smooth muscle cell proliferation, Ang II $\left(10^{-6} \mu \mathrm{M}\right)$ was initially employed to stimulate $\mathrm{A} 7 \mathrm{r} 5$ cells for $24 \mathrm{~h}$ and subsequently the cells were administrated with TFAM in different concentrations $(10-50 \mu \mathrm{g} / \mathrm{mL})$ for $24 \mathrm{~h}$. Cell viability was measured in 96-well plates by Cell Counting Kit-WST-8 (CCK-8) assay as our previous research (Zhou et al., 2015).

\section{Luciferase reporter assay}

The effect of Ang II on T-cell Factor (TCF)/ Lymphoid Enhancing Factor (LEF) family-dependent gene transcription was evaluated using the TOP-flash TCF reporter plasmid containing two sets of three copies of the TCF binding site upstream of the thymidine kinase (TK) minimal promoter and luciferase open reading frame (Millipore, Billerica, MA). A7r5 cells were co-transfected with TOP-flash or FOP-flash plasmid $(1 \mu \mathrm{g})$, and Renilla reporter plasmid $(0.1 \mu \mathrm{g})$ (pRL-TK; Promega). The cells were further cultured with or without Ang II $(1 \mu \mathrm{M})$ for 12 $\mathrm{h}$ in serum-free medium, and then sequentially post-treated with or without TFAM $(10-30 \mu \mathrm{g} / \mathrm{mL})$. Luciferase assay was determined using Luciferase Assay System (Promega, US).

\section{Statistical analysis}

Data were expressed as the means \pm standard deviation (SD) for at least three experiments (each in duplicate) and analyzed using a $t$-test or one-way ANOVA for comparison. The difference was considered significant if the probability was $<0.05(*)$ or $<0.01(* *)$.

\section{RESULTS}

\section{Ameliorative effects of TFAM on hemodynamic and physical parameters in spontaneously hypertensive rats}

The dosages of total flavonoids in TFAM-L, TFAM-M and TFAM-H, are $90 \mathrm{mg} / \mathrm{kg}, 180 \mathrm{mg} / \mathrm{kg}$ and $360 \mathrm{mg} / \mathrm{kg}$, respectively. No significant change in body weight was observed by the TFAM treatment. The average body weights of the animals at the end of the study (7 weeks) in the SHR untreated group, TFAM treated group and positive control group were $369.17 \pm 4.9,359.06 \pm 4.1$ and $366.2 \pm 4.13 \mathrm{~g}$, respectively. Moreover, no significant differences were observed in the liver, kidney and heart weights at the end of the experiments between different treatment groups.

Generally, the values of SBP and heart rate (HR) in SHRs without TFAM treatment were $182 \pm 8.6 \mathrm{~mm} \mathrm{Hg}$. To validate the antihypertensive effects of TFAM under in vivo conditions, TFAM were orally administered to SHRs with different concentrations followed by SBP measurements every week (Figure 1A). The maximum SBP decrease $(-21.1 \pm 4.46 \mathrm{mmHg})$ was obtained early in the experiment at 2 weeks, and the effect gradually
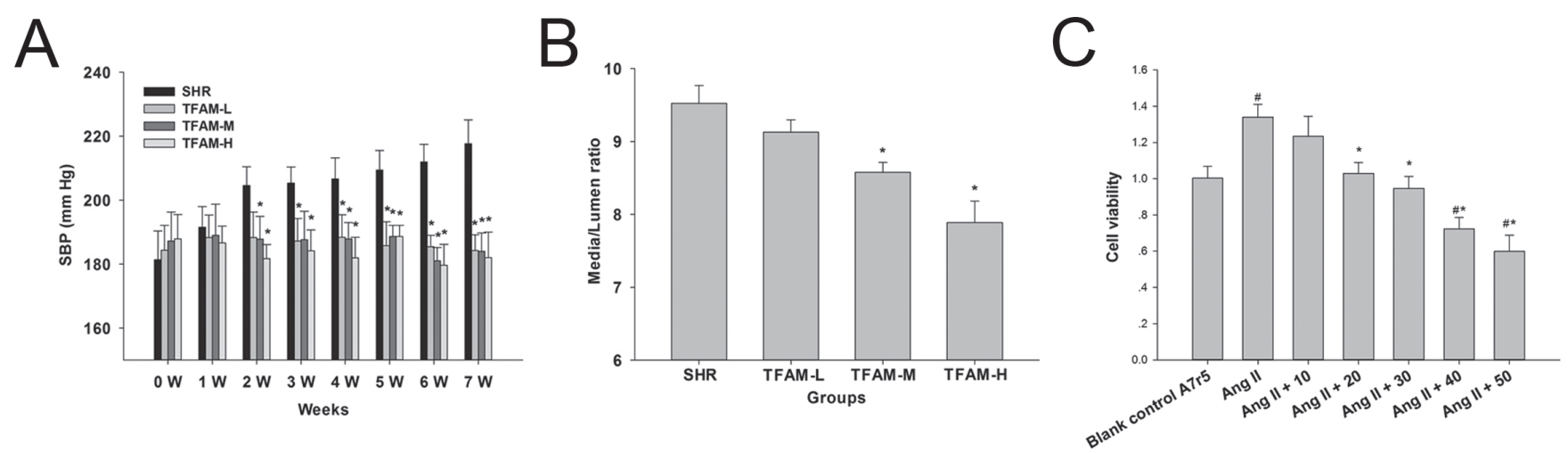

FIGURE 1 - TFAM ameliorated the hemodynamic and physical parameters in spontaneously hypertensive rats, and suppressed Ang II-induced A7r5 cell proliferation in Vitro. (A) TFAM restored the systolic blood pressure in SHRs. SBP (mmHg) values from untreated SHRs or those treated with TFAM (TFAM-L, $90 \mathrm{mg} / \mathrm{kg}$; TFAM-M $180 \mathrm{mg} / \mathrm{kg}$; TFAM-H, $360 \mathrm{mg} / \mathrm{kg}$ ) were recorded during light and dark cycles each week. Summary graphs to demonstrate the effects of TFAM on SBP. * indicates $\mathrm{P}<0.01$ compared to the SHR group. (B) TFAM attenuated the rate of media thickness versus lumen diameter. The media thickness of the thoracic aorta and lumen diameter were obtained in histologic sections, respectively. Data represented as mean $\pm \operatorname{SD}$ from $n=6$ rats per treatment group in (A) and (B), the values given are the mean $\pm \mathrm{SD}$ of three independent experiments. $* \mathrm{P}<0.05$ compared with the control SHR group. (C) CCK-8 assay was employed to evaluate the effects of TFAM on Ang II-induced A7r5 cell proliferation. A $7 \mathrm{r} 5$ cells were treated with $10-50 \mu \mathrm{g} / \mathrm{mL}$ for $24 \mathrm{~h}$. Cell viability was normalized to black control group. The values given are the mean \pm SD of five independent experiments. ${ }^{*} P<0.05$ compared to Ang II group. $\# P<0.05$ compared to blank control group. 
and significantly $(\mathrm{p}<0.05)$ enhanced from 3 to 7 weeks. Moreover, the HR in SHRs was observed with no significance among groups.

\section{TFAM reduced the rate of media thickness versus lumen diameter}

The media thickness of the thoracic aorta in SHR group was highly variable, with an average thickness of $136.96 \pm 7.23 \mu \mathrm{m}$. Compared with SHR group, the thoracic aorta had a significantly lower media thickness in TFAM treated group. We next evaluated whether the media thickness had an effect on the functional viability of thoracic aorta, especially on the endothelial function. To do so, the lumen diameter of thoracic aorta was investigated, and the rates of media thickness versus lumen diameter in each group were obtained. Compared to control group, the rate of media thickness versus lumen diameter in TFAM-H group was significantly reduced, suggesting that TFAM could attenuate the remodeling process of vascular smooth muscle cells in SHRs (Figure 1B).

\section{Serum nitric oxide level and aortic mRNA expression of eNOS, ACE and Ang II was altered by TFAM}

Treatment with TFAM elevated the serum level of nitric oxide (Figure 2A) and aortic mRNA expression of eNOS (Figure 2B).Aortic ACE and Ang II mRNA expression was suppressed by treatment with TFAM $(P<0.05)$ (Figure 2B). The results indicated that the activation of RAAS could be attenuated by TFAM in SHRs.
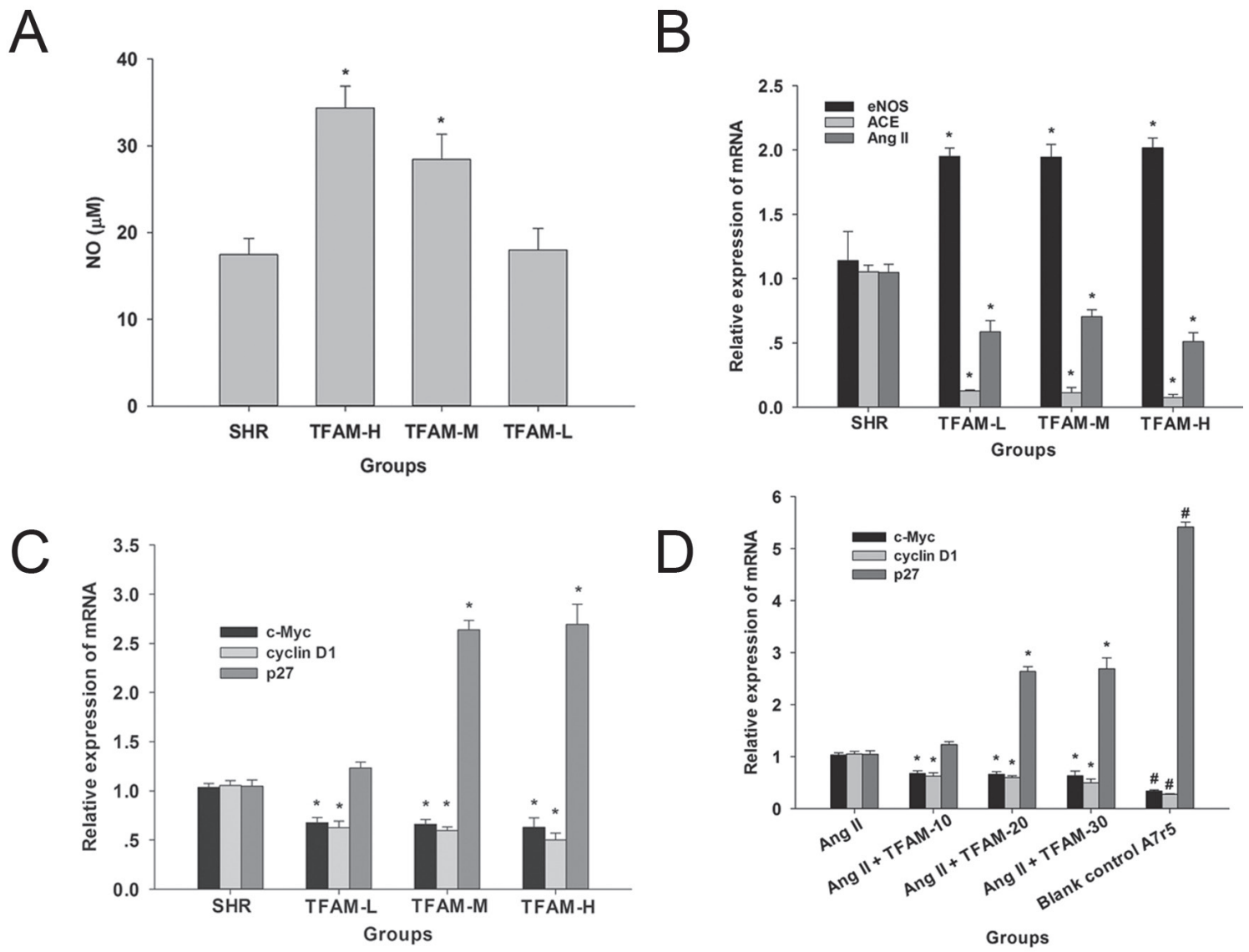

FIGURE 2 - Effects of TFAM on the serum nitric oxide level, and expressions of RAS and proliferation related genes in vascular smooth muscle cells. TFAM increased the release of nitric oxide in serum and altered the mRNA expressions of eNOS, ACE and Ang II. (A) The effects of TFAM on the content of nitric oxide. (B) The evaluation was estimated via qPCR analysis using mRNA from cells treated with TFAM and the process was described in Methods. (C) The effects of TFAM-L, TFAM-M, TFAM-H on the mRNA expressions of p27 ${ }^{\mathrm{Kip} 1}$, c-Myc and cyclin D1 in the thoracic aorta of SHRs. The values in (A, B, C) given are the mean \pm SD. $\mathrm{n}=6,{ }^{*} P<0.05$, compared with the SHR group. (D) The effects of TFAM $(10-20 \mu \mathrm{g} / \mathrm{mL})$ on the mRNA expressions of $\mathrm{p} 27^{\mathrm{Kip} 1}$, c-Myc and cyclin D1 in Ang II-stimulated A7r5 cells. Gene expression was estimated via qPCR analysis using mRNA from tissues or cells treated with TFAM and the process was described in Methods. The values given are the mean $\pm \mathrm{SD}$ of three independent experiments. ${ }^{*} P<0.05$ and $\# P<0.05$, compared with Ang II group in (D). 


\section{TFAM could suppress mRNA expression of proliferative and remodeling factors in vascular smooth muscle cells}

Cell cycle control is achieved by sequentially modulating multiple proteins including c-Myc, p2 $7^{\text {Kip1 }}$, and cyclin D1, which are modulated by Wnt signaling (Taipale, Beachy, 2001), and trigger the process of cell proliferation. Up-regulated expressions of proto-oncogenes in aorta in hypertensive rat models are also reported in previous studies (Naftilan, Pratt, Dzau, 1989). In our study, TFAM significantly reduced the mRNA expression of c-Myc and Cyclin D1 in SHRs (Figure 2C). Furthermore, our results showed that the mRNA expression of $\mathrm{p} 27^{\mathrm{Kip} 1}$, which could block the cell cycle (Toyoshima, Hunter, 1994), was elevated at TFAM-H group (Figure 2C).

Previous studies have demonstrated that overexpression of pro-oncogenes and aberrant proliferation of vascular smooth muscle cells (VSMCs) is Ang II dependent (Lyall et al., 1992). In Figure 1C, the data indicated that TFAM could inhibit the Ang II-induced proliferation of A7R5 cells in a dose-dependent manner at $10-50 \mu \mathrm{g} / \mathrm{mL}$. Considering the antiproliferative effects and cytotoxicity of TFAM in cell viability evaluation, the concentrations, $20-30 \mu \mathrm{g} / \mathrm{mL}$, were selected for further RNA and protein quantification. To identify whether c-Myc, Cyclin D1 and p2 $7^{\mathrm{Kip} 1}$ was involved in the inhibitory effect of TFAM on Ang II-induced A 7r5 VSMCs hypertrophy and proliferation, we also validated the expression of c-Myc, Cyclin D1 and p27 Kip1 by qPCR analysis in A7r5 cells. As expected, Ang II significantly enhanced c-Myc and Cyclin D1 expression, and suppressed the mRNA expression of $\mathrm{p} 27^{\mathrm{Kip} 1}$ in A7r5 cells. Moreover, c-Myc and Cyclin D1 expressions were significantly inhibited by TFAM post-treatment (Figure 2D). The evidence was further observed in the western blot assay (Figure 3 ), which suggested that TFAM at 20 and 30 $\mu \mathrm{g} / \mathrm{mL}$ could modulate the protein expressions of c-Myc, Cyclin D1 and $\mathrm{p} 27^{\mathrm{Kip} 1}$ in A7r5 cells. Thus, these data demonstrated that the regulation of c-Myc, Cyclin D1 and p2 $7^{\text {Kip } 1}$ by Ang II was involved in TFAM inhibitory effect on Ang II-induced VSMC hypertrophy and proliferation.

\section{Antiproliferative effects of TFAM is involved in canonical Wnt signaling pathway}

In consideration of the effects of TFAM on the expression c-Myc, we next evaluated the mediating role of TFAM on overall $\beta$-catenin levels in thoracic aorta cells of SHRs. However, the result was negative (Data not shown). Next, we presumed that TFAM might mediate the subcellular localization of $\beta$-catenin, and subsequently affect the $\beta$-catenin dependent transcriptional activity. As shown in Figure 4A, immunoblotting assay showed a relative decrease in nuclear $\beta$-catenin accumulation in cells with TFAM post-treatment as compared with those in control group. This result indicated that TFAM could decrease the accumulation of $\beta$-catenin in the nucleus, rather than the expression of $\beta$-catenin in A $7 \mathrm{r} 5$ cells.

The functional consequence of $\beta$-catenin accumulation was also estimated by using a luciferase reporter system. In Figure 4C, Ang II could induce $\beta$-catenin-mediated gene transcriptional activity in $\mathrm{A} 7 \mathrm{r} 5$ cells. Furthermore, the transcriptional activity induced
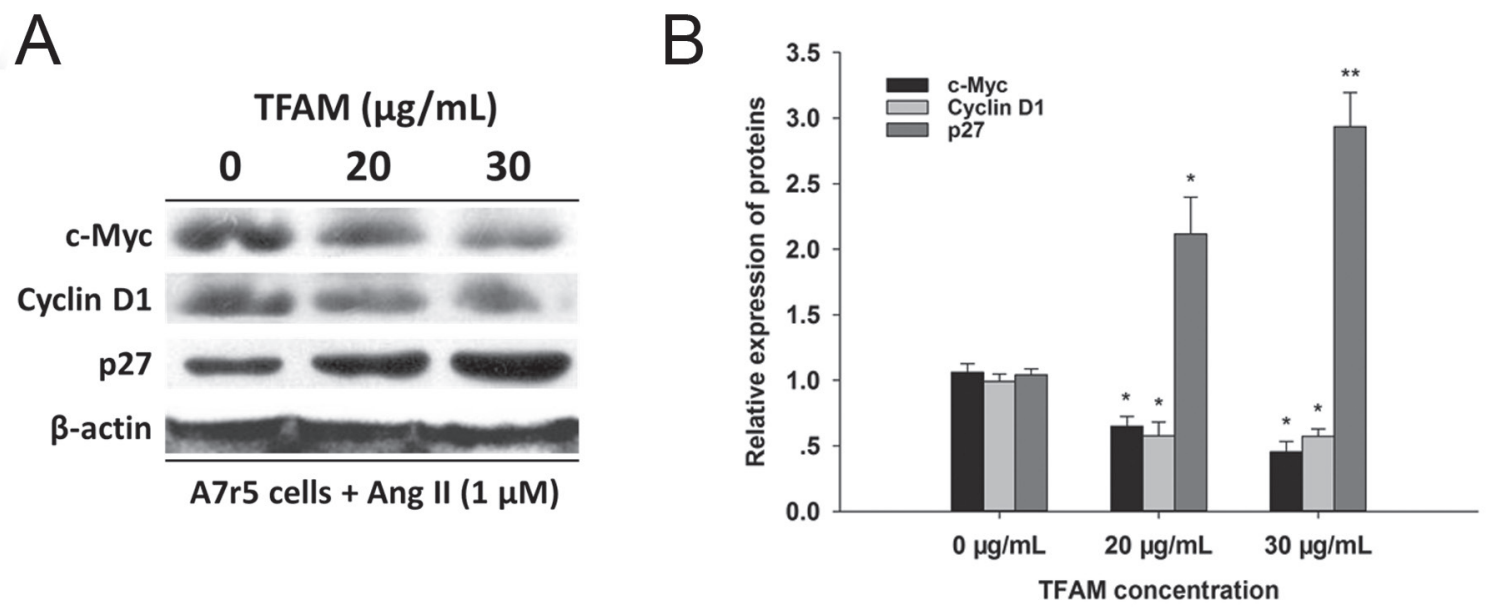

FIGURE 3 - TFAM suppressed protein expressions of c-Myc and Cyclin D1 and elevated the level of p27 ${ }^{\text {Kipl }}$ protein. (A) Protein expressions of c-Myc, Cyclin D1 and p2 $7^{\mathrm{Kip} 1}$ after $24 \mathrm{~h}$ of administration with 20 and $30 \mu \mathrm{g} / \mathrm{mL}$ of TFAM. (B) Bars represent the intensity of the bands of (A) quantitated by densitometry, respectively. No treatment control group was showed as $0 \mu \mathrm{g} / \mathrm{mL}$ of TFAM. Mean $\pm \mathrm{SD}, n=3$. $* P<0.05$ vs Ang II group; $* * P<0.01$ vs Ang II group. 

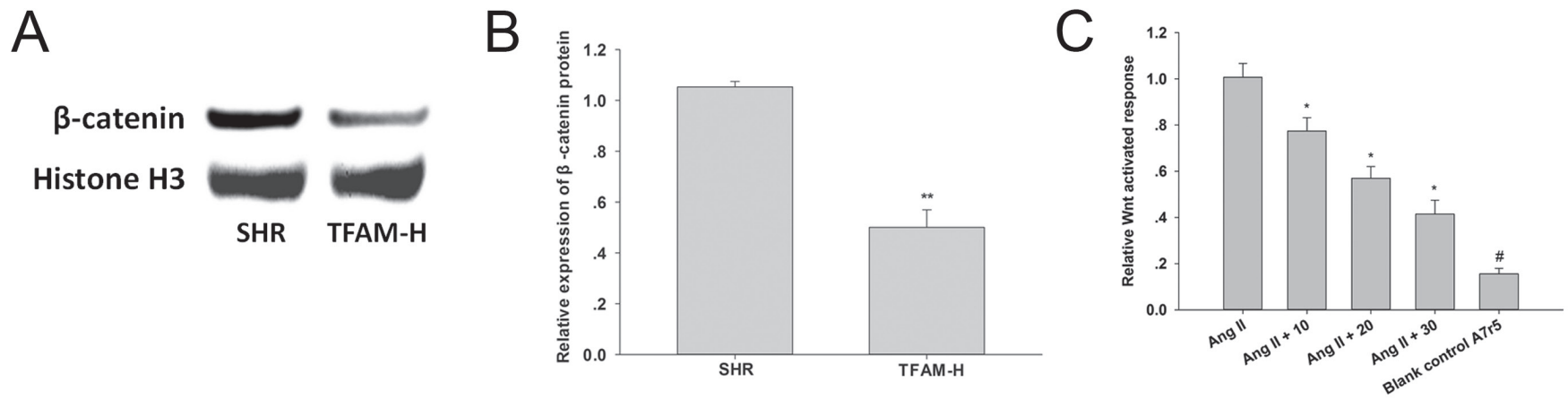

FIGURE 4 - TFAM could suppress Wnt/ $\beta$-catenin signaling in vascular smooth muscle cells. (A) TFAM decreased protein expression of $\beta$-catenin in western blot assay. (B) Bars represent the intensity of the bands of (A), quantitated by densitometry. The values given are the mean \pm SD. $n=3,{ }^{*} P<0.05$, compared with the SHR group. (C) The TOPflash luciferase assay showed the effect of TFAM on high activation of TCF/LEF transcription in Ang II-stimulated A7r5 cells. A7r5 cells were transfected with a TOPflash or FOPflash reporter construct and either TFAM or no treatment. The TOPflash luciferase activity was measured after $48 \mathrm{~h}$ posttreatment. Values represent the mean \pm SD. $n=3,{ }^{*} P<0.05$, for TFAM treated cells versus the cells in Ang II group. $\# P<0.05$, for cells of blank control group versus the cells in Ang II group.

by Ang II was suppressed in TFAM-M and TFAM-H, indicating that TFAM could suppress canonical Wnt signaling pathway both in rat vascular smooth muscle cells.

\section{DISCUSSION}

Some epidemiological evidence indicates that consumption of antioxidant-rich diet may alleviate hypertension. An alteration to a vegetable-based diet is also efficacious to relieve hypertension (Berkow, Barnard, 2005). In this study, we explore the novel observation that antihypertensive effects of flavonoids in A. megalophylla are involved in affecting the remodeling, and the expressions of tumor suppressor genes and protooncogenes in vascular smooth muscle cells.

Like the pathogenesis in most primary hypertensive patients, spontaneously hypertensive rats obviously exert the characteristic of chronical cardiovascular remodeling (Duarte et al., 2001). In the present study, the artery function in SHRs was facilitated by treatment for 7 weeks with total flavonoids in A. megalophylla. Moreover, we explore a novel observation that antihypertensive effects of TFAM are involved in affecting the vascular remodeling, and the expressions of tumor suppressor gene and protooncogene in vascular smooth muscle cells.

In essential hypertension, resistance vessels suffer RAS-mediated continuous contraction and chronic remodeling. Either in hypertrophic remodeling or inward eutrophic remodeling, media/lumen ratio is elevated, which is attributed to the adaptive adjustment of arteriole to physical of chemical irritation (Schiffrin, 1992). Also, the vascular remodeling contributes to pathological changes of organs in cardiovascular disease, suggesting that the suppression of resistance arterial remodeling could be considered as a therapeutic goal for preventing hypertension. In the present study, SHRs exposed to TFAM showed a statistically significant change in the media/lumen ratio reduction compared to SHRs with no TFAM treatment. The elevated media/lumen ratios of subcutaneous resistance arteries in SHRs undergo normalization within 7 weeks of the TFAM-based antihypertensive regimen. This observation suggests that normalization of the vascular structure appears to be correlated to the anti-hypertensive effects of TFAM.

Improving endothelium-dependent vascular relaxation by flavonoids is associated with reactivation of endothelium-derived nitric oxide activity (Fisher et al., 2003). In fact, it is agreeable that the cascade of RAS in endothelial cells could be effective to attenuate nitric oxide production. ACE is known to be a core factor in RAS, and increasing blood pressure by accumulating Ang II. Some flavonoids were demonstrated to exert inhibiting effects by directly chelating the zinc ion site of ACE (Actis-Goretta et al., 2003). Moreover, carbonyl and hydroxyl groups in flavonoids or derived compounds are considered as chelating agents to alter the ACE to inactive apoenzyme. Following 7-weeks application of TFAM, the level of nitric oxide and mRNA expression of eNOS were elevated in vivo, suggesting that the release of nitric oxide contributed to the antihypertensive effects of TFAM. Furthermore, the expressions of the negative regulators of endothelium-derived relaxing factors, ACE and Ang II, were suppressed by TFAM administration, demonstrating that the improved vascular function by TFAM was partly due to the inhibition of RAS. 
Excessive proliferation of vascular smooth muscle cells, inflammatory infiltrate of endothelium, and capillary fibrosis are all mechanisms that have been confirmed to accelerate arterial remodeling. Abnormal resistance vessels with increased media/lumen ratio are commonly accompanied with mild inflammation and exorbitant stacking of proliferation-related proteins (Intengan, Schiffrin, 2001). In vitro overexpression of $\mathrm{p} 27^{\mathrm{Kip} 1}$, a member of CIP/KIP family of CDK inhibitors, could suppress VSMC proliferation. Inversely, inhibition of p2 $7^{\text {Kip } 1}$ activity enhances primate aortic VSMC growth (Coqueret, 2003). Moreover, p2 $7^{\mathrm{Kip} 1}$-/- mice lost heparinregulated suppression of pneumatorexis induce pulmonary hypertension and vascular remodeling, indicating that $\mathrm{p} 27^{\mathrm{Kip} 1}$ is an essential suppressor of hypoxic pulmonary vascular remodeling (Yu et al., 2005). In the present study, the amount of $\mathrm{p} 27^{\mathrm{Kipl}}$ also increased in vessels from SHRs. Moreover, in the isolated VSMCs from SHRs with TFAM treatment, the mRNA expressions of c-Myc and cyclin D1 were significantly repressed. Hence, these findings suggest that VSMCs from hypertensive rats have an increased ability to respond to stimuli by TFAM, which provides a potential mechanism for TFAM to reduce the remodeling of the SHR vasculature.

The chronic influence of vascular remodeling involves in Wnt signaling cascades, which is conducting pathological proliferation of VSMCs, including reactivating glycogen synthase kinase $3 \beta$ (GSK $3 \beta$ ) by phosphorylating 9 -serine and obstructing $\beta$-catenin degradation. Generally, abundant $\beta$-catenin relocates to the nucleus and triggers transcriptional activity by binding T-cell factors/lymphoid-enhancing factors. Furthermore, the cascade could govern cell cycle via promoting the mRNA expression of c-Myc and cyclin D1 (Polakis, 2007). Thus, we attempted to confirm the effects of TFAM on the Wnt signaling. Our results showed that TFAM inhibited the expression of c-Myc and cyclin D1 in VSMCs through suppressing $\beta$-catenin accumulation in the nucleus. In A7r 5 cells, canonical Wnt/ $\beta$-catenin signaling was also activated by Ang II. Moreover, the $\beta$-catenin/TCF transcriptional activity is significantly repressed by $48 \mathrm{~h}$ post-treatment of TFAM. The abnormal accumulation $\beta$-catenin in the nucleus is also reduced by TFAM in VSMCs of SHRs, and the mRNA levels of c-Myc and cyclinD1 were subsequently downregulated. These data demonstrated that TFAM could suppress Wnt signaling by blocking the distribution of $\beta$-catenin in the nucleus, rather than by affecting the expression of $\beta$-catenin in cells.

Taken together, the potential mechanism of total flavonoids of $A$. megalophylla on VSMC proliferation in SHRs is proposed: with the synergistic effect of p2 $7^{\text {Kip } 1}$ activation, TFAM decreases mRNA expression of $\beta$-catenin and its downstream transcriptional factor, c-Myc and Cyclin D1, in sequence inhibits cell remodeling and the release of inflammatory mediators by suppressing RAS, following by triggering eNOS, and finally exerting the blood pressure lowering potential.

\section{ACKNOWLEDGEMENTS}

This work was supported by a grant from Hubei Provincial Department of Education (No. Q20162001) and a grant from Hubei University of Chinese Medicine (Qingmiao Project) for Dr. Zhenpeng Qiu.

\section{CONFLICT OF INTEREST}

The authors declare that they have no competing interests.

\section{ETHICS APPROVAL AND CONSENT TO PAR- TICIPATE}

Animal experiments were reviewed and approved by the Animal Research Central at the Hubei University of Chinese Medicine and conducted according to the principles of Guide for the Care and Use of Laboratory Animals in China.

\section{REFERENCES}

Actis-Goretta L, Ottaviani JI, Keen CL, Fraga CG. Inhibition of angiotensin converting enzyme (ACE) activity by flavan-3-ols and procyanidins. FEBS Lett. 2003;555(3): 597-600.

Bauersachs J, Bouloumie A, Mulsch A, Wiemer G, Fleming I, Busse R. Vasodilator dysfunction in aged spontaneously hypertensive rats: changes in NO synthase III and soluble guanylyl cyclase expression, and in superoxide anion production. Cardiovasc Res. 1998;37(3):772-779.

Beevers G, Lip GY, O'Brien E. ABC of hypertension: the pathophysiology of hypertension. BMJ. 2001;322(7921): $912-$ 916.

Berkow SE, Barnard ND. Blood pressure regulation and vegetarian diets. Nutr Rev. 2005;63(1):1-8.

Coqueret $\mathrm{O}$. New roles for $\mathrm{p} 21$ and $\mathrm{p} 27$ cell-cycle inhibitors: a function for each cell compartment? Trends Cell Biol. 2003;13(2):65-70. 
Duarte J, Perez-Palencia R, Vargas F, Ocete MA, Perez-Vizcaino F, Zarzuelo A, Tamargo J. Antihypertensive effects of the flavonoid quercetin in spontaneously hypertensive rats. Br J Pharmacol. 2001;133(1):117-124.

Filipeanu CM, Brailoiu E, Kok JW, Henning RH, De Zeeuw D, Nelemans SA. Intracellular angiotensin II elicits $\mathrm{Ca} 2+$ increases in A7r5 vascular smooth muscle cells. Eur J Pharmacol. 2001;420(1):9-18.

Fisher ND, Hughes M, Gerhard-Herman M, Hollenberg NK. Flavanol-rich cocoa induces nitric-oxide-dependent vasodilation in healthy humans. J Hypertens. 2003;21(12):2281-2286.

Galleano M, Pechanova O, Fraga CG. Hypertension, nitric oxide, oxidants, and dietary plant polyphenols. Curr Pharm Biotechnol. 2010;11(8):837-848.

Gibbons GH, Dzau VJ. The emerging concept of vascular remodeling. New Engl J Med. 1994;330(20):1431-1438.

Graham I, Atar D, Borch-Johnsen K, Boysen G, Burell G, Cifkova R, et al. European guidelines on cardiovascular disease prevention in clinical practice: executive summary. Fourth Joint Task Force of the European Society of Cardiology and other societies on cardiovascular disease prevention in clinical practice (constituted by representatives of nine societies and by invited experts). Eur J Cardiovasc Prev Rehabil. 2007;14(Suppl 2):E1-40.

Grassi D, Necozione S, Lippi C, Croce G, Valeri L, Pasqualetti P, Desideri G, Blumberg JB, Ferri C. Cocoa reduces blood pressure and insulin resistance and improves endothelium-dependent vasodilation in hypertensives. Hypertension. 2005;46(2):398405 .

Gu D, Reynolds K, Wu X, Chen J, Duan X, Muntner P, et al. Prevalence, awareness, treatment, and control of hypertension in china. Hypertension. 2002;40(6) 920-927.

Herrera-Arellano A, Miranda-Sanchez J, Avila-Castro P, Herrera-Alvarez S, Jimenez-Ferrer JE, Zamilpa A, et al. Clinical effects produced by a standardized herbal medicinal product of Hibiscus sabdariffa on patients with hypertension. A randomized, double-blind, lisinopril-controlled clinical trial. Planta Med. 2007;73(1):6-12.

Hodgson JM. Effects of tea and tea flavonoids on endothelial function and blood pressure: a brief review. Clin Exp Pharmacol Physiol. 2006;33(9):838-841.
Intengan HD, Schiffrin EL. Vascular remodeling in hypertension: roles of apoptosis, inflammation, and fibrosis. Hypertension. 2001;38(3 Pt 2):581-587.

Kearney PM, Whelton M, Reynolds K, Muntner P, Whelton PK, He J. Global burden of hypertension: analysis of worldwide data. Lancet. 2005;365(9455):217-223.

Lyall F, Dornan ES, McQueen J, Boswell F, Kelly M. Angiotensin II increases proto-oncogene expression and phosphoinositide turnover in vascular smooth muscle cells via the angiotensin II AT1 receptor. J Hypertens. 1992;10(12):14631469.

Naftilan AJ, Pratt RE, Dzau VJ. Induction of platelet-derived growth factor A-chain and c-myc gene expressions by angiotensin II in cultured rat vascular smooth muscle cells. J Clin Invest. 1989;83(4):1419-1424.

Perez-Vizcaino F, Ibarra M, Cogolludo AL, Duarte J, ZaragozaArnaez F, Moreno L, Lopez-Lopez G, Tamargo J. Endotheliumindependent vasodilator effects of the flavonoid quercetin and its methylated metabolites in rat conductance and resistance arteries. J Pharmacol Exp Ther. 2002;302(1):66-72.

Polakis P. The many ways of Wnt in cancer. Curr Opin Genet Dev. 2007;17(1):45-51.

Schiffrin EL. Reactivity of small blood vessels in hypertension: relation with structural changes. State of the art lecture. Hypertension. 1992;19(Suppl 2):II1-9.

Taipale J, Beachy PA. The Hedgehog and Wnt signalling pathways in cancer. Nature. 2001;411(6835):349-354.

Toyoshima H, Hunter T. p27, a novel inhibitor of G1 cyclin-Cdk protein kinase activity, is related to p21. Cell. 1994;78(1):67-74.

Wang Y, Qiu Z, Zhou B, Liu C, Ruan J, Yan Q, Liao J, Zhu F. In vitro antiproliferative and antioxidant effects of urolithin $\mathrm{A}$, the colonic metabolite of ellagic acid, on hepatocellular carcinomas HepG2 cells. Toxicol In Vitro. 2015;29(5):1107-1115.

Xie XF, Wang JW, Zhang HP, Li QX, Chen BY. Chemical composition, antimicrobial and antioxidant activities of essential oil from Ampelopsis megalophylla. Nat Prod Res. 2014;28(12):853-860. 
Xiong X, Yang X, Liu Y, Zhang Y, Wang P, Wang, J. Chinese herbal formulas for treating hypertension in traditional Chinese medicine: perspective of modern science. Hypertens Res. 2013;36(7):570-579.

Yu L, Quinn DA, Garg HG, Hales CA. Cyclin-dependent kinase inhibitor $\mathrm{p} 27 \mathrm{Kip} 1$, but not $\mathrm{p} 21 \mathrm{WAF} 1 / \mathrm{Cip} 1$, is required for inhibition of hypoxia-induced pulmonary hypertension and remodeling by heparin in mice. Circ Res. 2005;97(9):937-945.

Zhang Y, Que S, Yang X, Wang B, Qiao L, Zhao Y. Isolation and identification of metabolites from dihydromyricetin. Magn Reson Chem. 2007a;45(11):909-916.
Zhang YS, Zhang QY, Li LY, Wang B, Zhao YY, Guo DA. Simultaneous determination and pharmacokinetic studies of dihydromyricetin and myricetin in rat plasma by HPLCDAD after oral administration of Ampelopsis grossedentata decoction. J Chromatogr B Analyt Technol Biomed Life Sci. 2007b;860(1):4-9.

Zhou B, Yi H, Tan J, Wu Y, Liu G, Qiu Z. Anti-proliferative effects of polyphenols from pomegranate rind (Punica granatum L.) on EJ bladder cancer cells via regulation of $\mathrm{p} 53 / \mathrm{miR}-34 \mathrm{a}$ axis. Phytother Res. 2015;29(3):415-422.

Received for publication on $21^{\text {st }}$ November 2016 Accepted for publication on $16^{\text {th }}$ February 2017 